Journal of Environmental
ASSN: $2525-815 \mathrm{X}$

\title{
Avaliação do sensoriamento remoto termal para monitoramento de aterros sanitários
}

\section{Assessment of the thermal remote sensing for landfills monitoring}

\author{
Jadson Freire da Silva ${ }^{a}$, Rutt Keles Alexandre da Silva ${ }^{a}$, Yenê Medeiros Paz ${ }^{\text {a }}$, Josimar Vieira dos
} Reis $^{\mathrm{b}}$, Henrique dos Santos Ferreira ${ }^{\mathrm{c}}$, Ana Lúcia Bezerra Candeias ${ }^{\mathrm{a}}$

a Universidade Federal de Pernambuco-UFPE, Programa de Pós-Graduação em Desenvolvimento e Meio AmbientePRODEMA. Departamento de Ciências Geográficas, Cidade Universitária, Recife, Pernambuco, Brasil. CEP: 50740540. E-mail oijadsonfreire@icloud.com, ruttgeografia@gmail.com, yenemedeiros@ hotmail.com, analucia@ufpe.br.

b UFPE, Programa de Pós-Graduação em Desenvolvimento Urbano-MDU, Departamento de Arquitetura e Urbanismo, Cidade Universitária, Recife-PE, Brasil. CEP: 50740-550. E-mail: prej86@ gmail.com.

c UFPE, Programa de Pós-Graduação em Geografia-PPGEO, Departamento de Ciências Geográficas, Cidade Universitária, Recife-PE, Brasil. CEP: 50740-540. E-mail: henriquehs86@ hotmail.com.

\begin{tabular}{|c|c|}
\hline A R T I C L E I N F O & A B S T RA C T \\
\hline $\begin{array}{l}\text { Recebido } 25 \text { Jul } 2017 \\
\text { Aceito } 17 \text { Jan } 2018 \\
\text { Publicado 22 Jan } 2018\end{array}$ & $\begin{array}{l}\text { The daily presence of the garbage in the society makes necessary the reflection of the } \\
\text { environments of the same deposition: Which can be uncontrolled, configured as } \\
\text { dumps and causing various adversities for the surrounding population; or controlled, } \\
\text { this passive of monitoring their properties in order to reduce the effects they can } \\
\text { cause to the environment. Considering this perspective, remote sensing contributes } \\
\text { positively to the monitoring of these areas; analyzes can only be maintained in the } \\
\text { evolution of area size or other sensitive parameters. Understanding the importance } \\
\text { of temperature and its interactions with solid waste, this work aims to analyze thermal } \\
\text { remote sensing for landfill monitoring. It was used Landsat } 5 \text { and } 8 \text { images for the } \\
\text { region of Muribeca-PE (2006, 2016) and the Lixão da Estrutural-DF (2005, 2016) } \\
\text { applying radiative, reflectance, SAVI, IAF, emissivity and surface temperature. The } \\
\text { results showed a variation in the temperature of the Muribeca Landfill (2006) of } 6.1 \\
\text { degrees from the hottest point to the edge point; The new area of the Muribeca landfill } \\
\text { in } 2016 \text { ranged from } 7.8 ; \text { In turn, the old area remained at } 3.1 \text { degrees. The Structural } \\
\text { Landfill had a variation of } 5.2 \text { and } 8 \text { degrees in the years } 2005 \text { and } 2016 \text {, respectively. } \\
\text { Thermal remote sensing is of great relevance in the support of controlled and } \\
\text { uncontrolled landfill analyzes, however, several mishaps such as the periodicity of } \\
\text { the images and climatic conditions highlight the junction of the remote data with } \\
\text { those of the field for research. }\end{array}$ \\
\hline
\end{tabular}

Keywords: Geoprocessing, solid waste, garbage.

\section{R E S U M O}

A presença cotidiana do lixo na sociedade faz necessário a reflexão dos ambientes de deposição do mesmo; que pode ser não controlado, configurados como lixões e causando diversas adversidades para a população em entorno; ou controlado, este passivo do monitoramento de suas propriedades com propósito de reduzir os efeitos que podem causar ao ambiente. Nessa perspectiva, o sensoriamento remoto contribui positivamente no que tange ao monitoramento dessas áreas; as análises podem manter-se apenas na evolução de tamanho da área ou de outros parâmetros sensíveis. Compreendendo a importância da temperatura e suas interações com os resíduos sólidos, este trabalho tem como objetivo analisar o sensoriamento remoto termal para monitoramento de aterros. Utilizou-se imagens Landsat 5 e 8 para a região de Muribeca-PE $(2006,2016)$ e o Lixão da Estrutural-DF $(2005,2016)$ aplicando fórmulas de radiância, reflectância, SAVI, IAF, emissividade e de temperatura da superfície. Os resultados mostraram variação na temperatura do Aterro da Muribeca (2006) de 6,1 graus do ponto mais quente até o ponto de borda; a nova área do aterro 
da Muribeca em 2016, variou entre de 7,8; por sua vez, a área antiga manteve-se com 3.1 graus. O Lixão da Estrutural mostrou variação de 5,2 e 8 graus nos anos de 2005 e 2016, respectivamente. O sensoriamento remoto termal mostra-se de grande relevância no suporte das análises em aterros controlados e não controlados, todavia, diversos percalços como a periodicidade das imagens e condições climáticas ressaltam a junção dos dados remotos com os de campo para pesquisas.

Palavras-Chave: Geoprocessamento, resíduo sólido, lixo.

\section{Introdução}

O lixo é um material que está presente no cotidiano da sociedade no geral, podendo ser, para muitos, a fonte da renda no equilíbrio e manutenção familiar. No entanto, sua deposição inadequada o torna causador de consequências negativas ao meio ambiente. $\mathrm{O}$ lixo pode ser definido como os resíduos no estado sólido ou semissólidos, que resultam de atividades da comunidade de origem industrial, doméstica, hospitalar, comercial, agrícola, de serviços e de varrição, conforme Dalmázio et al. (2002). O destino destes resíduos em muitas cidades, ocasiona problemas de ordem social, política e ambiental.

Todos os dias, a quantidade de resíduos sólidos produzida pelos brasileiros tem aumentado consideravelmente. Segundo a Associação Brasileira de Empresas de Limpeza Pública ABRELPE (2011), pela primeira vez em 13 anos, o volume de lixo aumentou mais que o PIB nacional; esse aumento não era esperado, porém, a motivação para essa elevação na quantidade de resíduos foi o crescimento da população e o grande consumo de produtos descartáveis no país.

Devido à grande quantidade de lixo produzida pela população, o armazenamento dos resíduos sólidos nos lixões tem gerado discussões; situações que envolvem fatores como a ausência de fiscalização, resíduos jogados a céu aberto, ocasionando mal cheiro e contaminação manual, e disseminação de animais sinantrópicos - que vivem próximos às habitações humanas, adaptando-se a viver junto ao homem, a despeito da vontade deste (Morais, 2007). A contaminação do solo e de corpos hídricos pelo chorume, líquido produzido pelos processos físicos e químicos, juntamente com a decomposição das matérias orgânicas jogadas nos lixões, pode ser observada em todo o território nacional também pode ser levantado como percalço resultante de lixões.

Mesmo com as condições supracitadas, encontradas nos ambientes de lixões a céu aberto, famílias na linha da extrema pobreza sobrevivem através da coleta de materiais recicláveis a partir destes locais, estando assim sujeitas a adquirir doenças, sofrer acidentes e impactos sociais, dado que esses catadores não detêm garantia de emprego ou suporte em caso de enfermidades, encontrando no lixão a única alternativa de sobrevivência
(Freire, 2000). Além dos impactos sociais, os impactos gerados pelos lixões aumentam ainda mais os danos causados à natureza; Marques (2011), ressalta o processo de decomposição dos resíduos sólidos e a ocorrência de geração de gases como metano (CH4), óxido de nitrogênio (NOx), óxido de enxofre (SOx) e dióxido de carbono $\left(\mathrm{CO}_{2}\right)$, que são grandes responsáveis pelo aumento dos gases do efeito estufa. O estudo clássico de Andreottola \& Cossu (1988) afirma que a partir das reações aeróbicas e anaeróbicas a temperatura do lixo aumenta ao longo do tempo, principalmente nas camadas superiores. Junqueira (2000) discute a grande importância das temperaturas em ambientes deposicionais de resíduos sólidos no que se refere à atividade de microrganismos que promovem a degradação dos diversos componentes do lixo.

Observando a problemática dos lixões a céu aberto para a sociedade, o Estado brasileiro, aliando-se a outros países, estipulou uma meta envolvendo a substituição de lixões por aterros sanitários. A partir desse acordo entre diversos países foi promulgada a Política Nacional de Resíduos Sólidos-PNRS (Lei $\mathrm{n}^{\circ}$ 12.305/2010), a qual insere instrumentos importantes para a implantação de soluções que possam promover uma gestão eficiente dos resíduos sólidos, em ação conjunta com atividades benéficas ao ambiente físico natural e a sociedade em geral. Os aterros sanitários estão sendo criados com o intuito de diminuir o volume de lixo que é depositado nos lixões, uma vez que para confinar os resíduos são utilizados princípios da engenharia, reduzindo e realocando a área e o volume do material depositado, reduzindo os danos à saúde pública $\mathrm{e}$ os impactos ambientais. De acordo com a ABNT/NBR 10.004, recomenda-se a construção de aterros com vida útil mínima de 10 anos. O seu monitoramento deve prolongar-se, no mínimo, por mais 10 anos após o seu encerramento.

Nesse contexto, o sensoriamento remoto e o geoprocessamento têm se tornado ferramentas de extrema relevância no que se diz respeito a estudos voltados a aquisição de áreas, análise e monitoramento dos impactos ambientais. Essas tecnologias facilitam a coleta, o gerenciamento e a visualização espacial e temporal de dados relevantes, melhorando significadamente os diagnósticos ambientais e sócio sanitários Além dos estudos citados anteriormente, o sensoriamento 
remoto na especificidade termal apresenta uma série de aplicações potenciais, como estimativa do balanço de energia, teor de água em zona radicular, evapotranspiração, monitoramento de estiagens, determinação do estresse hídrico em plantas e avaliação de temperatura, sendo de particular interesse em estudos hidrológicos, meteorológicos e climáticos (Aghakouchak et al., 2015; Warren et al., 2014).

Analisando as dificuldades que os ambientes deposicionais de resíduos sólidos a céu aberto - lixões, proporcionam para a sociedade, sua relação com a temperatura e os benefícios do sensoriamento remoto termal para os estudos ambientais, este estudo tem como objetivo principal a análise do antigo lixão da Muribeca, em Recife-PE, uma área onde, atualmente, está localizado o aterro sanitário da Muribeca, e o Lixão da Estrutural, em Brasília-DF, considerando mudanças temporais e variações de temperatura.

\section{Material e Métodos}

\section{Área de estudo}

Na Região Metropolitana do Recife, há mais de três décadas, foram iniciadas atividades na área do então lixão da Muribeca, situado em Jaboatão dos Guararapes, com seus limites abrangendo um terreno de 60 ha. Apesar do substantivo Muribeca remeter, automaticamente, ao lixão que marcou a história do bairro de mesmo nome, convém pensar naquele ambiente como uma célula inserida em um contexto municipal maior (Figura 1).

O Aterro Controlado está na zona rural de Jaboatão, em uma localidade distante $16 \mathrm{~km}$ do centro da Cidade do Recife. Foi considerado, nada menos, que o maior aterro em atividade em Pernambuco, conforme afirmam Lins et al. (2011). Deve ser esclarecido que o encerramento e a recuperação do Aterro de Resíduos Sólidos da Muribeca se baseou no projeto Executivo de Encerramento Ambiental, formulado em conjunto com pesquisadores e professores da Universidade Federal de Pernambuco, em contrato firmado com a Empresa de Limpeza Urbana-EMLURB em 2008. O projeto foi aprovado, integralmente, pelo órgão ambiental estadual. Nisto, para encerramento do aterro em pauta estavam dois temas principais: "a necessidade de criação de uma baixa manutenção para os sistemas adotados $e$ a necessidade de conceber uma cobertura final a fim de minimizar a infiltração da precipitação para a massa de resíduos" (Lins et al., Op. Cit. p.2).

O que se pode afirmar hoje é que no Aterro de Resíduos Sólidos da Muribeca houve uma diminuição de impactos ambientais danosos. Do ponto de vista social, com o redirecionamento de atividades, para a maioria dos catadores que foram empregados em empresas de coleta, bem como construtoras e até mesmo no próprio Aterro da Muribeca. Sobre o ambiente natural, a minimização dos prejuízos aparece pelo sistema de cobertura final implantado para minimizar a infiltração e erosão (Ibidem), dois fatores que são potenciais causadores de danos ambientais, principalmente atuando em área deposicional de resíduos.

O Lixão da Estrutural está no noroeste do Distrito Federal, próximo ao Jóquei Clube, da cidade Estrutural e das águas que se juntam e formam o rio Paranoá. Mantendo uma área de 200 hectares, o lixão inicia-se nos anos 1960 resistindo até a atualidade, sendo considerado o maior aterro não controlado do Brasil e das Américas (Figura 1) (Ferreira \& Queiroz, 2015).

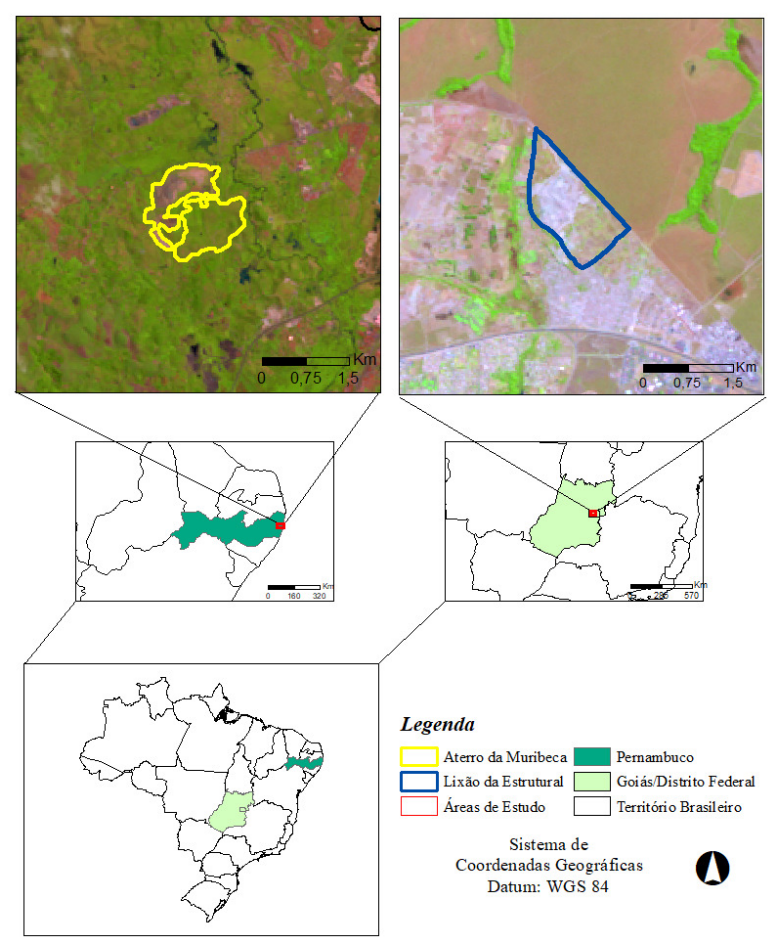

Figura 1. Mapa de localização das regiões de estudo.

\section{Processamento e aquisição dos dados Através do site gratuito} https://earthexplorer.usgs.gov/ foram obtidas as imagens referentes ao aterro sanitário da Muribeca para o ano de 2016 e 2006, do mesmo modo que ocorreu para as imagens do Lixão da Estrutural $(2005,2016)$. O empilhamento, reprojeção, recorte e aplicação de fórmulas foram manejados utilizando o software ERDAS Imagine 9.1, com licença no Departamento de Ciências Geográficas da Universidade Federal de Pernambuco.

\section{Radiância}


Também denominada de calibração radiométrica, essa etapa consiste em calcular a radiância espectral $\left(\mathrm{L}_{\gamma i}\right)$ de cada banda empilhada, a equação utilizada para este procedimento para o Landsat 5 é a dos pesquisadores Markham \& Baker (1987) (Equação 1):

$$
\mathrm{L}_{\gamma i}=a_{i}+\left(\frac{b_{i}-a_{i}}{254}\right)(\mathrm{ND}-1)
$$

onde o $a$ e $b$ são os coeficientes mínimo e máximos (Tabela 1) (Chander, Markham \& Helder, 2009), $i$ corresponde às bandas das imagens e ND ao número digital da mesma.

Tabela 1. Intervalos de comprimento de onda espectral, dados de coeficiente de calibração e da Irradiância no topo da atmosfera. Fonte: Chander, Markham \& Helder (2009).

\begin{tabular}{|c|c|c|c|c|c|c|}
\hline \multirow{2}{*}{ Bandas } & \multirow{2}{*}{$\begin{array}{l}\text { Comprimento de } \\
\quad \text { onda }(\mu \mathrm{m})\end{array}$} & \multicolumn{4}{|c|}{ Coeficientes de calibração } & \multirow{2}{*}{$\begin{array}{c}\text { Irradiância espectral no topo } \\
\text { atmosférico - TOA }\end{array}$} \\
\hline & & a & b1 & b2 & b3 & \\
\hline 1 (azul) & $0.452-0.518$ & -1.52 & 152.10 & 193.0 & 169.0 & 1957 \\
\hline 2 (verde) & $0.528-0.609$ & -2.84 & 296.81 & 365.0 & 333.0 & 1796 \\
\hline 3 (vermelho) & $0.626-0.693$ & -1.17 & 204.30 & 264.0 & 264.0 & 1536 \\
\hline 4 (IV - próximo) & $0.776-0.904$ & -1.51 & 206.20 & 221.0 & 221.0 & 1031 \\
\hline 5 (IV - médio) & $1.567-1.784$ & -0.37 & 27.19 & 30.2 & 30.2 & 220.0 \\
\hline $6(\mathrm{IV}$ - termal $)$ & $10.45-12.42$ & 1.2378 & 15.303 & 15.303 & 15.303 & - \\
\hline 7 (IV - médio) & $2.097-2.349$ & -0.15 & 14.38 & 16.5 & 16.0 & 83.44 \\
\hline
\end{tabular}

Considerando o Landsat 8, soma-se os termos aditivos e multiplicativos da radiância encontrados no arquivo Metadados multiplicado pelo número digital (Equação 2) (Silva et al., 2016).

$\operatorname{Add}_{r a d, b}+$ Mult $_{r a d, b} \cdot \mathrm{ND}_{b}$

Eq.(2)

\section{Reflectância}

A refletância $\left(\rho_{\gamma i}\right)$ consiste pela divisão entre o fluxo de radiação solar refletida pelo fluxo de radiação solar que se incide, sendo desenvolvida para o satélite Landsat 5 pela equação de Allen et al. (2002, 2007) (Equação 3):

$\rho_{\gamma i}=\frac{\pi \cdot \mathrm{L}_{\gamma i}}{\mathrm{k}_{i} \cdot \cos Z \cdot d_{r}}$

$d_{r}=1+0,033 \cos \left(D S A \cdot \frac{2 \pi}{365}\right)$

onde o $\mathrm{L}_{\gamma i}$ é a radiância calculada anteriormente, $\mathrm{k}_{i}$ é a Irradiância solar no topo da atmosfera (Tabela 1) e Z é o ângulo zenital. Para obtenção do $d_{r}$ (distância terra sol), resgatamos a equação de Iqbal (1983) (Equação 4), onde o DSA representa o dia sequencial do ano.

Para o Landsat 8, utiliza-se, para computar a reflectância, valores do $\operatorname{Add}_{r e f, b}$ e Mult $_{r e f, b}$ que refletem termos aditivos e multiplicativos de cada banda empilhada obtidos no metadados; o $\mathrm{ND}_{b}$ retratando os números digitais dos pixels, $\mathrm{Z}$ para o ângulo zenital e $\mathrm{d}_{r}$ para correção da órbita terrestre (Equação 5) (Silva et al., 2016).
$\mathrm{r}_{b}=\frac{\left(\operatorname{Add}_{r e f, b}+\mathrm{Mult}_{r e f, b} \cdot \mathrm{ND}_{b}\right)}{\operatorname{cosZd}_{r}}$

Eq.(5)

Para o cálculo da reflectância deve-se, para obter o d $\mathrm{d}_{r}$ da Equação 5, aplicar a Equação 6:

$\mathrm{d}_{r}=\left(\frac{1}{\mathrm{~d}_{e s}}\right)^{2}$

onde o $\mathrm{d}_{e s}$ é a distância média terra sol.

Após a obtenção dos produtos de reflectância, foram calculados os índices de vegetação ajustado ao solo e a área foliar. O Índice de Vegetação Ajustado ao Solo (SAVI/IVAS) foi desenvolvido por Huete (1988), onde o pesquisador reduz o efeito do solo na imagem (Equação 7).

$\mathrm{SAVI}=\frac{(1+\mathrm{L})\left(\mathrm{P}_{\mathrm{IV}}-\mathrm{P}_{\mathrm{V}}\right)}{\left(\mathrm{L}+\mathrm{P}_{\mathrm{IV}}+\mathrm{P}_{\mathrm{V}}\right)}$

onde $\mathrm{P}_{\mathrm{IV}}$ e $\mathrm{P}_{\mathrm{V}}$ são as bandas 4 (infravermelho próximo) e 3 (vermelho). O L é a constante de variação do solo.

O Índice de Área Foliar - IAF/LAI depende do SAVI e consiste na divisão entre a área foliar da vegetação pela unidade utilizada de vegetação por área (Equação 8) (Allen et al., 2002).

$\mathrm{IAF}=-\frac{\log \frac{(0,69-\mathrm{SAVI})}{0,59}}{0,91}$

onde o SAVI é o Índice de vegetação ajustado ao solo. 
A emissividade permite medir quanto o corpo tem tendência de emitir radiação. Para execução da formula de temperatura de superfície, é essencial o cálculo da emissividade da banda estreita (de pixel a pixel) (Equação 9) (Allen et al., 2002, 2007).

$\varepsilon_{\mathrm{NB}}=0,97+0,0033 . \mathrm{IAF}$

onde o IAF é o Índice de área foliar.

A temperatura da superfície é calculada pela banda termal e pela emissividade da banda estreita. A formula consiste, segundo Souza \& Silva (2005), da inversão da função de Plank, com seu produto final em graus Kelvin (Equação 10) (Allen et al., 2002, 2007).

$\mathrm{T}_{\mathrm{s}}=\frac{\mathrm{K}_{2}}{\log \left(\frac{\varepsilon_{\mathrm{NB}} \mathrm{k} 1}{\mathrm{~L}_{\gamma 6}}+1\right)}$

onde $\varepsilon_{\mathrm{NB}}$ é a emissividade, o $\mathrm{L}_{\gamma 6}$ é a radiância da banda termal e os K (K1 e K2) são constantes da banda termal, disponibilizadas nos metadados da imagem.

Os dados de temperatura em graus Kelvin foram convertidos para Celsius.

\section{Análise e confecção dos mapas}

As análises, classificação dos histogramas em intervalos e confecção dos mapas foram executados a partir do software ArcGIS 9.2, licenciado pelo Departamento de Ciências Geográficas da Universidade Federal de Pernambuco.

\section{Resultados}

Sabe-se que a temperatura em ambientes deposicionais de resíduos sólidos afeta propriedades, tanto na esfera física, quanto na química, biológica e mecânica. Hartz et al. (1982) identificaram faixas de grande potencial para decomposição e degradação de resíduos sólidos oriundas de temperatura. Rowe (1998), relatou a presença de elevadas temperaturas (até 70 graus Celsius) para os resíduos em diversas faixas de decomposição, onde apontou como o aumento de temperatura as atividades microbiológicas aeróbica e anaeróbica e suas emissões de gases inflamáveis (Hogland \& Marques, 2003; Leite, 1973). Villarrubia \& Villarrubia (2001) afirmaram que o período seco é o mais propício ao risco de autocombustão de materiais, não só pelas iterações entre as bactérias, mas também pela presença do material seco em abundância. Mesmo com pesquisas sobre a tema sendo executada ao longo dos anos, o assunto lixo ainda é pouco explorado, quando se compara com outras pesquisas.
Estudos sobre o monitoramento da temperatura do lixo in loco foram realizados por Yesiller \& Hanson (2003), onde eles constataram que os resíduos de borda e de profundidades rasas ou superficiais apresentam flutuações semelhantes às flutuações sazonais da temperatura do ar. Além disso, estes pesquisadores observaram que os novos resíduos mantêm temperatura superior aos resíduos mais antigos (Hanson, Yesiller \& Swarbrick, 2005). Mariano \& Moura (2009) observaram que, durante o período seco, existe uma diferença na transferência da radiação solar incidente na superfície para as camadas mais profundas, no que tange aos momentos diurnosnoturnos. Estes autores também verificaram que, no período seco, as temperaturas encontradas nas camadas superficiais são mais elevadas que as das camadas inferiores e que o processo inverso ocorre no período chuvoso.

$\mathrm{O}$ uso do geoprocessamento e do sensoriamento remoto para o monitoramento de aterros é observado em diversos estudos. Yang et al. (2008) avaliaram ameaças potenciais de lixiviação em aterros na China, utilizando o geoprocessamento, pontuando as concentrações de compostos orgânicos e a proximidade de corpos hídricos. Silvestri \& Omri (2008) identificaram e validaram, através de assinaturas espectrais, os aterros não controlados na região nordeste da Itália, utilizando imagens IKONOS e fotos aéreas. Choudhury \& Das (2012) e Ohri et al. (2015), utilizando o cruzamento hierárquico dos planos de informações, selecionaram os melhores locais para a aplicação de novos aterros nas cidades de Dharmanagar (Nagar Panchayet) e Varasi, na Índia, respectivamente.

Ainda considerando essa temática, Monsef (2015), manuseando dados socioeconômicos e ambientais, apontou regiões potenciais para aterros nos municípios costeiros do Egito. Manzo et al. (2016), através de diversos índices, entre eles de temperatura e vegetação, investigaram a influência antrópica de uso do solo após despejos de extração mineral no Parque Nacional Monte Vesuvius, na Itália. Kwarteng \& Al-Enezi (2004), através de um levantamento temporal de imagens de médio e baixa resolução e seus índices, avaliaram um aterro não controlado no Kuwait, o qual causava problemas, desde um forte mau cheiro, até problemas de saúde pública devido à proximidade com habitações.

Percebe-se que, através de extensos levantamentos de pesquisas em publicações nacionais e internacionais, as metodologias aplicadas para avaliar, analisar e/ou diagnosticar aterros controlados e não controlados variam caso a caso, respeitando os dados disponibilizados, o 
tamanho da região de interesse e a experiência relatada. Indo de encontro ao que foi pesquisado em âmbito acadêmico, com fins de visualização, apresentamos a distribuição temporal dos ambientes selecionados para este estudo, usando uma composição RGB (Figura 2).

A Figura $2 \mathrm{AB}$ mostra dois períodos relativos à presença do ambiente da Muribeca, isto porque, durante o período entre 1984 até 2009, o aterro sanitário da Muribeca era um lixão a céu aberto (representado no mapa pelo layer escuro), sendo criado, inicialmente, como "aterro emergencial" e com vida útil prevista de cinco anos, contando a partir de sua criação (Arruda, 2015; Santos, 2007).

Enquanto na Região Metropolitana do Recife eram realizados novos estudos para a aquisição de um local adequado para depositar os resíduos sólidos, o lixão da Muribeca foi um pleno indicador de problemas sociais, ambientais, sanitários e da ausência de políticas públicas (Estadão, 2001; Diário de Pernambuco, 2008). Buscando solucionar a situação da Muribeca, em 2008 foi firmado o projeto de encerramento do aterro não controlado, sendo definitivamente desativado em 2009, onde, além de ser realocado para um aterro sanitário controlado (Figura $2 \mathrm{AB}$, layer azul), foram executadas atividades mitigadoras no antigo local, tais como capacitação dos antigos catadores de lixo, reflorestamento e bombeamento do chorume (Jornal do Commercio, 2013).

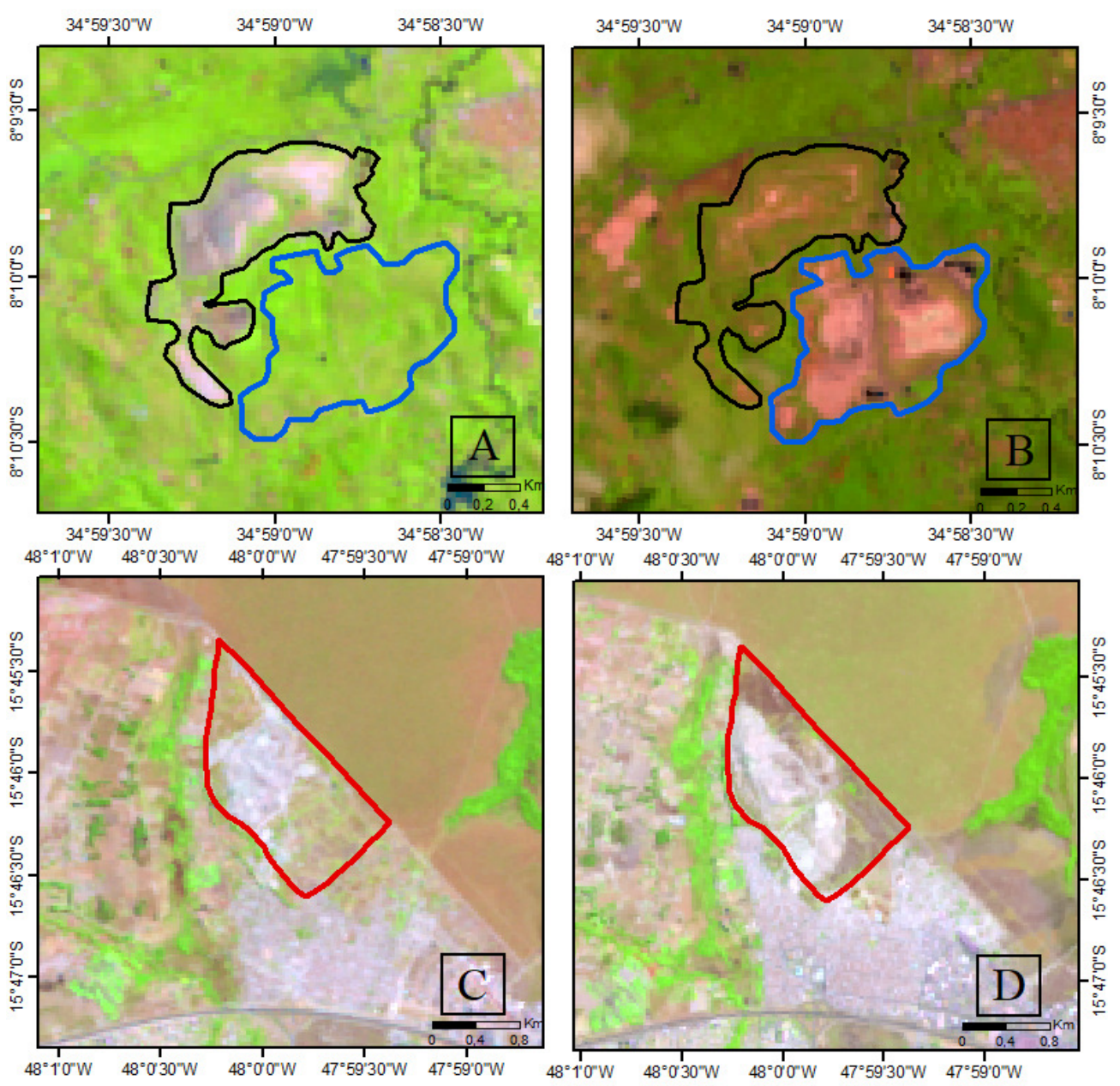

Composições RGB (5/4/3) do Aterro Sanitário da Muribeca (PE) e Lixão da Estrutural (DF)
A - B: Aterro sanitário da Muribeca, Região Metropolitana de Recife, Pernambuco
A - Área do Aterro Sanitário da Muribeca - 26/08/2006
B: Área do Aterro Sanitário da Muribeca - 06/09/2016
C - D: Lixão da Estrutural, Brasília, Distrito Federal
C - Área do Lixão da Estrutural - 24/08/2005
D: Área do Lixão da Estrutural - 22/08/2016

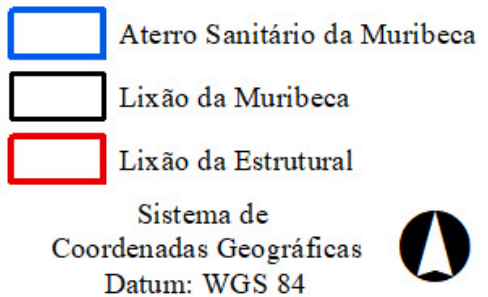

Figura 2. Composições RGB para o Aterro Sanitário da Muribeca (PE) e Lixão da Estrutural (DF). 
A Figura 2CD (layer vermelho) apresenta o maior lixão do Brasil na atualidade e o maior da América Latina em atividade: o lixão da Estrutural. Datado desde a década de 1960, este ambiente abriga, além dos problemas ambientais, mazelas sociais marcantes, como o trabalho infantil, a insalubridade e a violência (BBC, 2016; Metrópoles, 2017ab). Sob as promessas e incertezas de encerramento do lixão para 2017, a cidade cada vez mais vem se aproximando do lixão, com o passar dos anos (EBC, 2017; Pereira \& Queiroz, 2015).

A Figura 3 mostra a viabilidade do monitoramento através de imagens Landsat 5 e 8 para observação de aterros controlados e não controlados devido à dimensão das áreas de estudo.
A Figura 3A revela uma mancha de elevada temperatura onde estava alocado o antigo lixão da Muribeca. Em contrapartida, a Figura 3B apresenta a mancha de temperatura no aterro controlado, região adjacente ao lixão sete anos após o seu término.

As atividades de compensação as perdas ambientais citadas no estudo de Lins et al. (2011) tais como o plantio de gramíneas e espécies da mata atlântica conduzem a temperatura da região do antigo lixão para menores patamares, resultado satisfatório no que tange a gestão ambiental integrada. Resultado que pode ser observado através da Figura 3B, em que a temperatura da superfície do antigo lixão foi reduzida após seu encerramento.

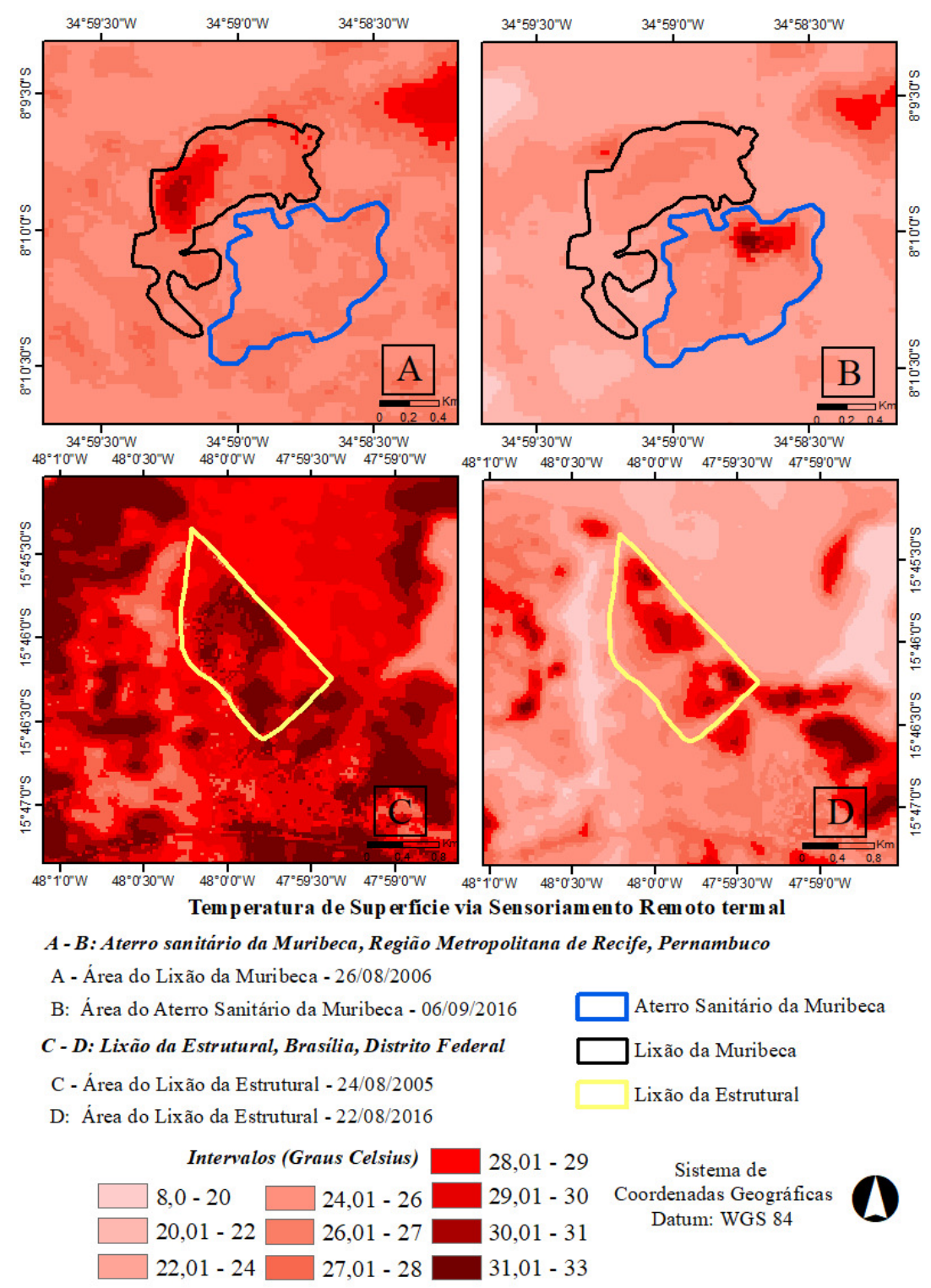

Figura 3. Mapas da temperatura da superfície para o Aterro Sanitário da Muribeca (PE) e Lixão da Estrutural (DF).

O lixão da Estrutural, representado pela Figura 3CD, exibe, em seus domínios, diversas células de temperatura elevada. Os dados da Tabela
2 foram utilizados para uma análise quantitativa das oscilações na temperatura de superfície dos aterros. 
Tabela 2. Variações nas temperaturas da superfície para o Aterro Sanitário da Muribeca (PE) e Lixão da Estrutural (DF). A. Lixão da Muribeca (26/08/2016), B. Aterro Sanitário da Muribeca (06/09/2016), C. Lixão da Estrutural (24/08/2016), D. Lixão da Estrutural (22/08/2016).

\begin{tabular}{cccccc} 
Mapas da Figura 3 & $\begin{array}{c}\text { Ponto mais } \\
\text { quente }\end{array}$ & $\begin{array}{c}\text { Ponto mais } \\
\text { frio }\end{array}$ & $\begin{array}{c}\text { Ponto } \\
\text { médio }\end{array}$ & Diferença & Área dos Aterros \\
\hline \multirow{2}{*}{ Imagem A 2006 } & 30.6 & 24.5 & 27.55 & 6.1 & Lixão da Muribeca \\
& 27 & 24.8 & 25.9 & 2.2 & Aterro Sanitário \\
Imagem B 2016 & 27 & 23.9 & 25.45 & 3.1 & Lixão da Muribeca \\
& 31.6 & 23.8 & 27.7 & 7.8 & Aterro Sanitário \\
Imagem C 2006 & 33.1 & 27.9 & 30.5 & 5.2 & Lixão da Estrutural \\
& & & & & \\
Imagem D 2016 & 31.5 & 23.5 & 27.5 & 8 & Lixão da Estrutural \\
\hline
\end{tabular}

O atual Aterro da Muribeca, em Pernambuco, considerado de médio porte, apresentou, para o ano de 2006, temperaturas na área do antigo lixão $\left(30,6^{\circ} \mathrm{C}\right.$ no ponto mais quente, $24,5^{\circ} \mathrm{C}$ na zona de borda) variando $6,1^{\circ} \mathrm{C}$ do ponto mais quente até a zona mais fria. No ano de 2016, sete anos após a desativação do antigo lixão, o aterro sanitário da Muribeca obteve variação de $7,8^{\circ} \mathrm{C}$ graus do ponto mais quente do lixo a zona de borda. A área do antigo lixão, através de políticas de mitigação ambiental, apresentou para o ano de 2016 variação de temperatura de $3,1^{\circ} \mathrm{C}$, valores semelhantes são verificados na área destinada ao aterro da Muribeca em 2006.

Detectou-se no lixão da Estrutural em Brasília, considerado de grande porte, uma variação de temperatura em sua área de $5^{\circ} \mathrm{C}$ (2006) $-8^{\circ} \mathrm{C}$ (2016), com as células mais quentes acima de $30^{\circ} \mathrm{C}\left(33.1^{\circ} \mathrm{C} ; 31.5^{\circ} \mathrm{C}\right)$ e as mais frias no intervalo de 23 a 28 graus Celsius. Além disso, é possível observar a partir das composições RBG (Figura 2CD) o avanço de habitações próximas aos depósitos de lixo, podendo ocasionar problemas de cunho social e sanitário para esses residentes.

\section{Discussão}

Oscilações na temperatura em lixões, seja na superfície ou em profundidades variadas, são extensamente determinadas em diferentes partes do mundo, conforme verificado no estudo de Lacoboaea \& Petrescu (2013) que monitoraram, através de sensoriamento remoto, a temperatura em uma série temporal de 30 anos, em um dos maiores aterros da Romênia. Yan et al. (2014) realizaram uma análise multitemporal em uma área de disposição municipal de resíduos sólidos em Ontário no Canadá, utilizando imagens de satélite Landsat no período de 1984 a 2011. Beaumont, Radoux \& Defourny (2014) detectaram, através de sensoriamento remoto aéreo e orbital, alterações de temperatura em aterros na Tunísia, Bélgica e França.

No Brasil, Monteiro \& Jucá (1999), monitorando as células do lixão da Muribeca, in loco, observaram temperaturas aproximadas aos $60^{\circ} \mathrm{C}$, em profundidades inferiores a cinco metros, com valores, na superfície, próximos ao intervalo de $29^{\circ} \mathrm{C}-32^{\circ} \mathrm{C}$; resultados aproximados são encontrados nos estudos de Rowe (1998) e Mariano \& Moura (2009), em relação à temperatura dos resíduos em profundidade.

Avaliando a diferença entre o pico mais quente e a zona de borda do aterro, observa-se concordância com os estudos (ou resultados) de Kwarteng \& Al-Enezi (2004) e Silvestri \& Omri (2008), onde a utilização de imagens com resolução de 1 metro (IKONOS) mostrou que a temperatura do aterro apresentou valores superiores àquelas do entorno, com variação entre $1^{\circ} \mathrm{C}$ e $4^{\circ} \mathrm{C}$, indicando a relevância dos produtos IKONOS para o acompanhamento destas áreas. No levantamento temporal de Lacoboaea \& Petrescu (2013), utilizando imagens Landsat 5, a temperatura do aterro mostrou um aumento entre $2^{\circ} \mathrm{C} \mathrm{a} 8^{\circ} \mathrm{C}$ em relação às áreas de borda. Além disso, os autores citados pontuaram questões pertinentes a aplicação do sensoriamento remoto termal, tais como a dependência das condições climáticas para um monitoramento mensal e a impossibilidade de coleta dos dados situados abaixo do solo.

Dificuldades são encontradas em relação a aquisição de imagens para o monitoramento de aterros controlados e não controlados, principalmente em regiões litorâneas. A elevada presença de nuvens ainda é um grande obstáculo para as diferentes aplicações do sensoriamento remoto. 
Através dos dados obtidos verificou-se que a estimativa da temperatura da superfície oriunda do sensoriamento remoto é de extrema importância para estudos em aterros e lixões, conforme discutido por outros autores (Yang et al., 2008; Silvestri \& Omri, 2008; Choudhury \& Das, 2012; Ohri et al., 2015). Contudo, considera-se relevante a complementação com dados de campo visto que a temperatura do solo e abaixo deste pode apresentar variações, de acordo com os estudos de Yesiller \& Hanson (2003), Hanson, Yesiller \& Swarbrick (2005), Mariano e Moura (2009) e Rowe (1998).

A gratuidade das imagens Landsat, a ampla disponibilidade de dados de períodos anteriores e a combinação com dados presenciais podem ser considerados pontos positivos na avaliação do uso de ferramentas de sensoriamento remoto para análises ambientais, indicando ser um excelente suporte na análise e gestão de ambientes deposicionais, como aterros.

\section{Conclusão}

A importância do sensoriamento remoto como ferramenta auxiliar para monitorar aterros ambientes deposicionais de resíduos sólidos foi confirmada. Esta é considerada uma ferramenta auxiliar, pois a resolução da banda termal é de 100 metros para o Landsat 8 e 120 metros para o Landsat 5, diferente das bandas na faixa do visível que possuem 30 metros de resolução. Esta dificuldade não é encontrada nos estudos onde são utilizados satélites com alta resolução, como o IKONOS. Todavia, para obter monitoramentos contínuos, diferente do Landsat, que é gratuito, deve-se dispor de significantes parcelas de capital financeiro.

Dificuldades encontradas na literatura relativas à aplicação do sensoriamento remoto, tais como a dependência das condições climáticas para monitoramento semanal/mensal - presença de nuvens; periodicidade no imageamento do satélite Landsat, impedindo o acompanhamento diário e a impossibilidade de coletar dados de temperatura ínferos ao solo, reforçam o geoprocessamento e o sensoriamento remoto termal como auxiliar na gestão de aterros.

É possível estimar os valores de temperatura em profundidade a partir dos resultados do sensoriamento remoto termal $\mathrm{e}$ literatura relativa às análises físico-químicas para aterros. Contudo, este estudo não minimiza a importância das coletas de dados in loco, ao contrário, estas devem ser estimuladas.

\section{Agradecimentos}

Agradecemos à agência de fomento Fundação de Amparo à Ciência e Tecnologia de Pernambuco. À Universidade Federal de Pernambuco, especificamente aos Laboratórios Análise e Processamento de Imagens (Departamento de Engenharia Cartográfica e Agrimensura) e Geoprocessamento e Sensoriamento Remoto (Departamento de Ciências Geográficas) pelo uso de suas instalações e colaborações nas análises. Em especial ao Laboratório de Pesquisas Geográficas NUVEM.

\section{Referências}

AGHAKOUCHAK, A.; FARAHMAND, A.; MELTON, F. S.; TEIXEIRA, J.; ANDERSON, M. C.; WARDLOW, BRIAN D.; HAIN, C. R. 2015. Remote sensing of drought: Progress, challenges and opportunities. Rev. Geophys., v. 53, p. 452-480.

ALLEN, R.; TASUMI, M.; TREZZA, R. 2007. Satellite-Based Energy Balance for Mapping Evapotranspiration with Internalized Calibration METRI. Model. J. Irrig. Drain Eng., v. 133, p. 380-394.

ALLEN， R.; TASUMI， M.; TREZZA， R.; BASTIAANSSEN, W.; WATERS, R. 2002. SEBAL (Surface Energy Balance Algorithms for Land). Advanced Training and User's Manual Idaho Implementation, version 1.0.

ANDREOTTOLA, G.; COSSU, R. 1988. Modello matematico di produzione del biogas in uno scarico controllato (mathematical model of biogas production). Rifiuti Solidi, v. 2, p. 473.

ARRUDA, S. G. 2015. Avaliação do mercado informal de reciclagem como atividade relevante ao processo de gerenciamento de resíduos sólidos, após encerramento de lixões: o caso de Aguazinha e Muribeca. Dissertação de Mestrado, Universidade Federal de Pernambuco, CAA, Programa de Pós-Graduação em Engenharia Civil, 101p.

ASSOCIAÇÃO BRASILEIRA DE EMPRESAS DE LIMPEZA PÚBLICA E RESÍDUOS SÓLIDOS-ABRELPE. 2011. Panorama dos resíduos sólidos no Brasil. Disponível em: http://www.abrelpe.org.br/Panorama/panorama2 011.pdf. Acesso em: 23/12/2017.

ASSOCIAÇÃO BRASILEIRA DE NORMAS TÉCNICAS-ABNT. 1987. NBR. 10.004. Resíduos sólidos: classificação. Rio de Janeiro. 
BBC BRASIL. 2016. Galeria do Lixão da Estrutural-DF. Disponível em: http://www.bbc.com/portuguese/noticias/2016/0 3/160310_galeria lixao estrutural_pdf. Acesso em: 20/05/2017.

BEAUMONT, B; RADOUX, J; DEFOURNY, P. 2014. Assessment of airborne and spaceborne thermal infrared remote sensing for detecting and characterizing landfills. Waste Management and The Environment VII, v. 180, p. 237-248.

CHANDER, G.; MARKHAM, B. L.; HELDER, D. L. 2009. Summary of current radiometric calibration coefficients for Landsat MSS, TM, ETM+, and EO-1 ALI sensors. Remote Sensing of Environment., v. 113, p. 893-903.

CHOUDHURY, C.; DAS, S. 2012. GIS and Remote Sensing for Landfill Site Selection-A Case Study on Dharmanagar Nagar Panchayet. IOSR (International Organization of Scientific Research) Journal of Environmental Science, Toxicology and Food Technology, v. 1, n. 20, p. 36-43.

DALMÁZIO, I.; OLIVEIRA, A. H.; MENEZES, M. A. B. C.; SILVA, M. R. S.; VASCONCELOS, D. C.; SANTOS, B. L. 2002. Avaliação da contaminação por metais associado ao despejo de chorume no Rio Cururupe - lhéus - BA utilizando k0-INAA e ICP-MS. In: 6 th Meeting on Nuclear Applications - International Nuclear Atlantc Conference, Rio de Janeiro. CD ROM.

DIÁRIO DE PERNAMBUCO. 2008. A novela chamada lixão da Muribeca. Disponível em: https://rebelo.org/2008/uma-novela-chamadalixao-da-muribecal.Acesso em: 20/06/2017.

EBC-EMPRESA BRASIL DE COMUNICAÇÃO. 2017. Lixão da Estrutural. Disponível em: http://www.ebc.com.br/lixao-daestrutural. Acesso em 05/05/2017.

ESTADÃO. 2001. Prefeito de Jaboatão interdita lixão da Muribeca. Disponível em: http://brasil.estadao.com.br/noticias/geral,prefeit o-de-jaboatao-interdita-lixao,20010815p20343.

Acesso em 20/05/2017.

FREIRE, M. 2000. Angú de sangue. Editora Atelie, Ed. 1, 144p.

HANSON, J. L.; YESILLER, N.; SWARBRICK, G. E. 2005. Thermal analysis of GCLs at a municipal solid waste landfill. Waste
Containment and Remediation, Proceedings of Geo-Frontiers. Congress, Austin, TX, USA, ASCE, Reston, VA, pp. 3269-3283.

HARTZ, K. E.; KLINK, R. E.; HAM, R. K. 1982. Temperature Effects: Methane Generation from Landfill Samples. Journal of Environmental Engineering, ASCE, v. 108, ee4, p. 629-638.

HOGLAND, W.; MARQUES, M. 2003. Physical, biological and chemical processes during storage and spontaneous combustion of waste fuel. Resources. Conservation and Recycling, v. 40, p. 53-69.

HUETE, A.R. A. 1988. Soil-Adjusted Vegetation Index (SAVI). Remote Sensing of Environment, v.25, p.295-309.

IQBAL, M. 1983. An introduction to solar radiation. Library of Congress Cataloging in Publication Data. Canada: Academic Press, 408p.

JORNAL DO COMMERCIO. 2013. Chorume do antigo lixão da Muribeca deve ser bombeado para aterro particular. Disponível em: http://jconline.ne10.uol.com.br/canal/cidades/cie nciamambiente/noticia/2013/04/17/chorume-doantigo-lixao-da-muribeca-deve-ser-bombeadopara-aterro-particular-80035.php. Acesso em: 20/05/2017.

JUNQUEIRA, F. F. 2000. Análise do Comportamento de Resíduos Urbanos e Sistemas Dreno Filtrantes em Diferentes Escalas, com Referência ao Aterro do Jóquei Clube-DF. Tese de Doutorado, Universidade Federal de Brasília, 283p.

KWARTENG, A. Y.; AL-ENEZI, A. 2004. Assessment of Kuwait's Al-Qurain landfill using remotely-sensed data. Journal of Environmental Science and Health, Part A Toxic/Hazardous Substances and Environmental Engineering, v. 39, p. 351-364.

LACOBOAEA, C.; PETRESCU, F. 2013. Landfill monitoring using remote sensing: a case study of Glina, Romania. Waste Management \& Research, v. 31, n. 10, p. 1075-1080.

LEITE, L. E. H. B. da C. 1973. Manual de limpeza pública. Instituto Brasileiro de Administração Municipal. Laboratório de Administração Municipal, Rio de Janeiro. 
LINS, E. A. M.; LINS, C. M. M. S.; BRITO, A. R.; BRITO, E. P. L.; SOUZA, N. N. 2011. Encerramento e recuperação do Aterro de resíduos sólidos urbanos da Muribeca. In: $26^{\circ}$ Congresso Brasileiro de Engenharia Sanitária e Ambiental. Anais ... pp. 1-6.

MANZO, C.; MEI, A.; FONTINOVO, G.; ALLEGRINI, A.; BASSANI, C. 2016. Integrated remote sensing for multi-temporal analysis of anthropic activities in the southeast of Mt. Vesuvius National Park. J. Afr. Earth Sci., v. 122, p. 63-78.

MARIANO, G. L.; MOURA, M. A. L. 2009. Comportamento da temperatura do lixo em duas épocas distintas (seca e chuvosa) no lixão da cidade de Maceió, AL. Ciência e Natura, UFSM, v. 31, n. 2 , p. $57-70$.

MARKHAM, B. L.; BARKER, L. L. 1987. Thematic mapper bandpass solar exoatmospherical irradiances. International Journal of Remote Sensing, v. 8, n. 3, p. 517-523.

MARQUES, R. F. P. V. 2011. Impactos ambientais da disposição de resíduos sólidos urbanos no solo e na água superficial em três municípios de Minas Gerais. Dissertação de Mestrado em Recursos Hídricos em Ciências Agrícolas. Universidade Federal de Lavras.

METRÓPOLES. 2017a. Catadores do Lixão da Estrutural encontram perna humana. Disponível em: $\quad$ http://www.metropoles.com/distritofederal/catadores-encontram-perna-no-lixao-daestrutural-policia-investiga. Acesso em: 20/07/2017.

METRÓPOLES. 2017b. Homem é encontrado morto no Lixão da Estrutural. Disponível em: http://www.metropoles.com/distritofederal/homem-e-encontrado-morto-no-lixao-daestrutural-policia-investiga. Acesso em: 22/07/2017.

MONSEF, H. ABD-EL. 2015. Optimization of municipal landfill siting in the Red Sea coastal desert using geographic information system, remote sensing and a analytical hierarchy process. Environmental Earth Sciences, v 74, n. 3, p. 22832296.

MONTEIRO, V. E. D.; JUCÁ, J. F. T. 1999. Gestão ambiental no processo de recuperação da área do aterro de resíduos sólidos de Muribeca.
Anais.... In: III Encontro da Sociedade Brasileira de Economia Ecológica. Recife, pp 1-9.

MORAIS, I. L. A. 2007. Controle de animais sinantrópicos em estabelecimentos de assistência à saúde: proposta de norma técnica. Dissertação de Mestrado. Faculdade de Ciências Médicas da Santa Casa de São Paulo, Curso de PósGraduação em Saúde Coletiva, 144f.

OHRI, A.; SINGH, P. K.; MAURYA, S. P.; MISHRA, S. 2015. Sanitary Landfill Site Selection by Using Geographic Information System. Proceedings of National Conference on Open Source GIS: Opportunities and Challenges Department of Civil Engineering, IIT (BHU), Varanasi, pp. 170-180.

PEREIRA, R. R; QUEIROZ, A. C. 2015. O Lixão de Brasília: O esforço para fechar o último grande depósito descontrolado de lixo das Américas. Revista Retrato do Brasil, Política, pp. 1-16.

POLÍTICA NACIONAL DE RESÍDUOS SÓLIDOS. $2^{\text {a }}$ edição, publicada no Diário Oficial da União, Seção 1, de 3 de agosto de 2010; Atualizada 18/5/2012.

ROWE, R. K. 1998. Geosynthetics and the Minimization of Contaminant Migration through Barrier Systems Beneath Solid Waste. Proceedings... Sixth International Conference on Geosynthetics, IFAI, pp. 27-102.

SANTOS, S. M. 2007. Gerenciamento do destino final dos resíduos sólidos municipais na região metropolitanas do Recife: históricos e proposições. Tese de Doutorado. Universidade Federal de Pernambuco. CTG. Pós-Graduação em Engenharia Civil. Recife.

SILVA, B. B.; BRAGA, A. C.; BRAGA, C. B.; OLIVEIRA, L. M. M.; MONTENEGRO, S. M. G. L.; BARBOSA JÚNIOR, B. 2016. Procedures for calculation of the albedo with OLI-Landsat 8 images: Application to the Brazilian semi-arid. Revista Brasileira de Engenharia Agrícola e Ambiental, v. 20, n. 1, p. 3-8.

SILVESTRI, S.; OMRI, M. 2008. A method for the remote sensing identification of uncontrolled landfills: formulation and validation, International Journal of Remote Sensing, v. 29, n. 4, p. 975-989.

SOUZA, J. D.; SILVA, B. B. 2005. Correção atmosférica para temperatura da superfície obtida 
com imagem TM - Landsat 5. Revista Brasileira de Geofísica, v. 23, n. 4, p. 349-358.

VILLARRUBIA, M.; VILLARRUBIA, J. 2001. Producción de biogás en vertederos de Residuos Sólidos Urbanos (RSU). Montajes e instalaciones, n. 355 , p. $95-104$.

WARREN, M. S.; TEIXEIRA, A. H. de C.; RODRIGUES, L.N.; HERNANDEZ, F. B. T. 2014. Utilização do Sensoriamento Remoto Termal na Gestão de Recursos Hídricos. Revista Brasileira de Geografia Física, v. 7, n. 1, p. 65-82.

YAN, W. Y.; MAHENDRARAJAH, P.; SHAKER, A.; FAISAL, K.; LUONG, R.; ALAHMAD, M. 2014. Analysis of multi-temporal landsat satellite images for monitoring land surface temperature of municipal solid waste disposal sites. Environ. Monit. Assess., v. 186, p. 8161-8173.

YANG, K.; ZHOU, X-N.; YAN, W-A.; HANG, D-R.; STEINMANN, P. 2008. Landfills in Jiangsu province, China, and potential threats for public health: Leachate appraisal and spatial analysis using geographic information system and remote sensing. Waste Management, v. 28, p. 2750-2757.

YESILLER, N.; HANSON, J. L. 2003. Analysis of Temperatures at a Municipal Solid Waste Landfill. Ninth International Waste Management and Landfill Symposium, Eds., CISA, Sardinia, Italy, pp. 1-10. 